\title{
Preference of Medical Students of Formaldehyde Preserved Cadaveric Dissection Versus Pre-Dissected Specimens as a Teaching Tool in Human Anatomy
}

\author{
Thisara Weerasuriya ${ }^{1,2,3,4}$,Francis Chan ${ }^{1}$, Surangi Yasawardene ${ }^{2}$ and Narendra Pinto ${ }^{2,4}$ \\ ${ }^{1}$ Tameside General Hospital, Manchester, UK \\ ${ }^{2}$ The Faculty of Medical Sciences, University of Sri Jayewardenepura, Sri Lanka \\ ${ }^{3}$ Ayr University Hospital, Ayr, Scotland, UK \\ ${ }^{4}$ The National Hospital of Sri Lanka, Sri Lanka
}

Correspondence should be addressed to: Thisara Weerasuriya; drthisara@yahoo.co.uk

Received date: 8 October 2013; Accepted date: 10 December 2013; Published date: 14 February 2014

Academic Editor: Yoshiyuki Tohno

Copyright @ 9 2014. Thisara Weerasuriya, Francis Chan, Surangi Yasawardene and Narendra Pinto. Distributed under Creative Commons CC-BY 3.0

\begin{abstract}
This study was conducted with a view of identifying the preference of first and second year medical students pertaining to the use of cadaveric dissections and pre-dissected specimens in the teaching of anatomy. A pre-validated questionnaire was used to evaluate the opinion of the students of the first and second years of the said medical school every year. Eighty five percent of the students during their first year liked dissections. Out of the $15 \%$ who expressed a dislike, $89 \%$ were female first year students. This was mainly due to the apprehension they had towards a human cadaver. Cadaveric dissections as well as pre-dissected specimens play an important role in the teaching of human anatomy. Cadaveric dissection provides the opportunity for students to gain a much more comprehensive insight into the human body in more holistic context. Dissections also help to develop skills which may be helpful to students who intend to follow further training in surgical specialities.
\end{abstract}

Keywords: cadaveric dissections, training in surgical, Formaldehyde Preserved, Human anatomy.

\section{Introduction}

This study was conducted in a medical school funded by the state in Sri Lanka from 2003 to 2008 over a period of five years. Anatomy is taught as part of the curriculum to medical students during the first two years in the medical school.
Human anatomy is a major part of the core education necessary for the understanding of further medical sciences, and is considered to be one of the basic sciences in medicine. A major change in the curriculum was undertaken in the said medical school in this period, and a serious thought was given about the teaching of anatomy, and the tools used for the purpose of teaching the subject. The authors decided to investigate the opinion of the students regarding

Cite this Article as: Thisara Weerasuriya, Francis Chan, Surangi Yasawardene and Narendra Pinto (2014), "Preference of Medical Students of Formaldehyde Preserved Cadaveric Dissection Versus Pre-Dissected Specimens as a Teaching Tool in Human Anatomy", JMED Research, Vol. 2014 (2014), Article ID 460465, 
their impression as to what tools help them in understanding a subject which is generally considered to be difficult.

Supervised cadaveric dissections involving about ten students per group in two dissection rooms with 15-20 formaldehyde preserved cadavers are made available during a period of three to four hours in the afternoons, daily for five days of the week. Anatomy demonstrators guide the students in their dissections.

In addition to the above, pre-dissected specimens demonstrating key anatomical relationships were also used in the teaching during lectures and small group discussion sessions as well as during dissection sessions in the afternoons.

The availability of human cadavers is not a cost to the university at all due to the Buddhist cultural belief that donation of human cadavers by the consent of the deceased prior to their demise (as in organ donation) conveys merit to the deceased person. Hence, the supply of cadavers to the medical school is not at all a financial issue and numbers have not been a handicap.

\section{Method}

A pre-validated questionnaire was used to evaluate the opinion of the students of the first and second years of the said medical school every year. The questionnaire was selfadministered and a separate information leaflet was provided with instructions. No further clarifications were provided. The questionnaire was in English as the medium of teaching in all medical schools in the country is English.

Each batch of students had the opportunity to express their views twice during their first two years which gave the authors information at two different levels of student maturation.

A simple scoring system of one to five to indicate the degree of satisfaction was used in individual aspects under investigation by the authors. According to this scale, five indicated maximum satisfaction while one indicated minimum satisfaction. The same questionnaire was administered at the end of the first year and at the end of the second year after the second MBBS examination which is held at the end of the second year. This examination consists of an MCQ paper with 60 MCQs in anatomy, a structured essay paper with six questions out of which five need to be answered, a spot test where students are expected to identify 40 anatomical structures and answer one or two questions based on the structure identified. Finally there is a ten minute viva voce on anatomy at this examination. The idea of administering the questionnaire at the end of this examination was to identify how the teaching tools were useful for the students to face this daunting examination.

The questionnaire focused on the following aspects.

- Demographic details of the student including gender

- Whether the student was happy with dissections?

- Whether they are comfortable with dealing with a cadaver?

o Whether they were emotionally disturbed?

- Whether they were physically affected by the cadaver being preserved in formaldehyde?

- Did they gain manual dexterity skills by dissecting the cadaver?

- Did the student think that dissections of the cadaver will help them in surgical skills later on in life?

- Did the students find pre-dissected specimens useful in their learning experience?

- Did they think that pre-dissected specimens should be used instead of cadavers to teach anatomy?

- Did the student feel distanced from the greater context of the human body due to the use of pre-dissected specimens in the teaching of anatomy?

- Did the student think that both teaching tools should be used in the teaching of anatomy?

The above aspects were looked into by the authors and the response of the students was recorded in a pooled data sheet. The data sheets were done separately for the first year students and the second year students.

\section{Results}

A total of 963 students were involved in this study over a period of five years.

Forty one percent of the students interviewed were females, and fifty nine percent of the students were males. All first year students thought that both pre-dissected specimens as 
well as the cadaveric dissections were beneficial for them in understanding human anatomy better. In contrast, $99 \%$ of the second year students thought that cadaveric dissections helped them understand the subject better, and all of them thought that cadaveric dissections improved their hand skills which they thought might be useful in pursuing a future career in surgery.

Table 1: Female and male students

\begin{tabular}{|l|l|}
\hline Female students & Male students \\
\hline 395 & 568 \\
\hline
\end{tabular}

Table 2: Student views on the usefulness of each teaching tool

\begin{tabular}{|l|l|l|l|}
\hline $\begin{array}{l}\text { Year of study of } \\
\text { students }\end{array}$ & $\begin{array}{l}\text { Cadaveric dissections } \\
\text { are more helpful }\end{array}$ & $\begin{array}{l}\text { Pre-dissected } \\
\text { specimens are more } \\
\text { helpful }\end{array}$ & $\begin{array}{l}\text { Both are equally } \\
\text { helpful }\end{array}$ \\
\hline First Year & - & - & $100 \%$ \\
\hline Second Year & $99.89 \%$ & - & - \\
\hline
\end{tabular}

Table 3: Student views on hand skill development

\begin{tabular}{|l|l|l|l|}
\hline $\begin{array}{l}\text { Year of study of } \\
\text { students }\end{array}$ & $\begin{array}{l}\text { Dissections help } \\
\text { development of hand } \\
\text { skills }\end{array}$ & $\begin{array}{l}\text { Pre-dissected } \\
\text { specimens } \\
\text { development of hand } \\
\text { skills }\end{array}$ & Not quite sure \\
\hline First Year & $46.6 \%$ & - & $53.4 \%$ \\
\hline Second Year & $98.7 \%$ & - & $1.3 \%$ \\
\hline
\end{tabular}

Table 4: Student views on surgical skill development

\begin{tabular}{|l|l|l|}
\hline The Year of study of students & $\begin{array}{l}\text { Dissections will help in future } \\
\text { surgical skills being developed }\end{array}$ & $\begin{array}{l}\text { Dissections will not help in } \\
\text { developing surgical skills }\end{array}$ \\
\hline First year & $32 \%$ & $68 \%$ \\
\hline Second year & $79.2 \%$ & $20.8 \%$ \\
\hline
\end{tabular}

Table 5: Student views on distancing from the human body by avoiding dissections

\begin{tabular}{|l|l|l|}
\hline The Year of study of students & $\begin{array}{l}\text { By avoiding dissections students } \\
\text { felt that they were distanced } \\
\text { from the human body }\end{array}$ & $\begin{array}{l}\text { By avoiding dissections students } \\
\text { don't think that they were } \\
\text { distanced from the human body }\end{array}$ \\
\hline First year & $43.4 \%$ & $56.6 \%$ \\
\hline Second year & $75.3 \%$ & $23.7 \%$ \\
\hline
\end{tabular}

Eighty five percent of the students during their first year liked dissections. Out of the $15 \%$ who expressed a dislike $89 \%$ were female first year students. This was mainly due to the apprehension they had towards a human cadaver. Two percent of first year students reported that they developed excessive tearing and breathing difficulties due to the cadavers emanating formaldehyde vapour. 


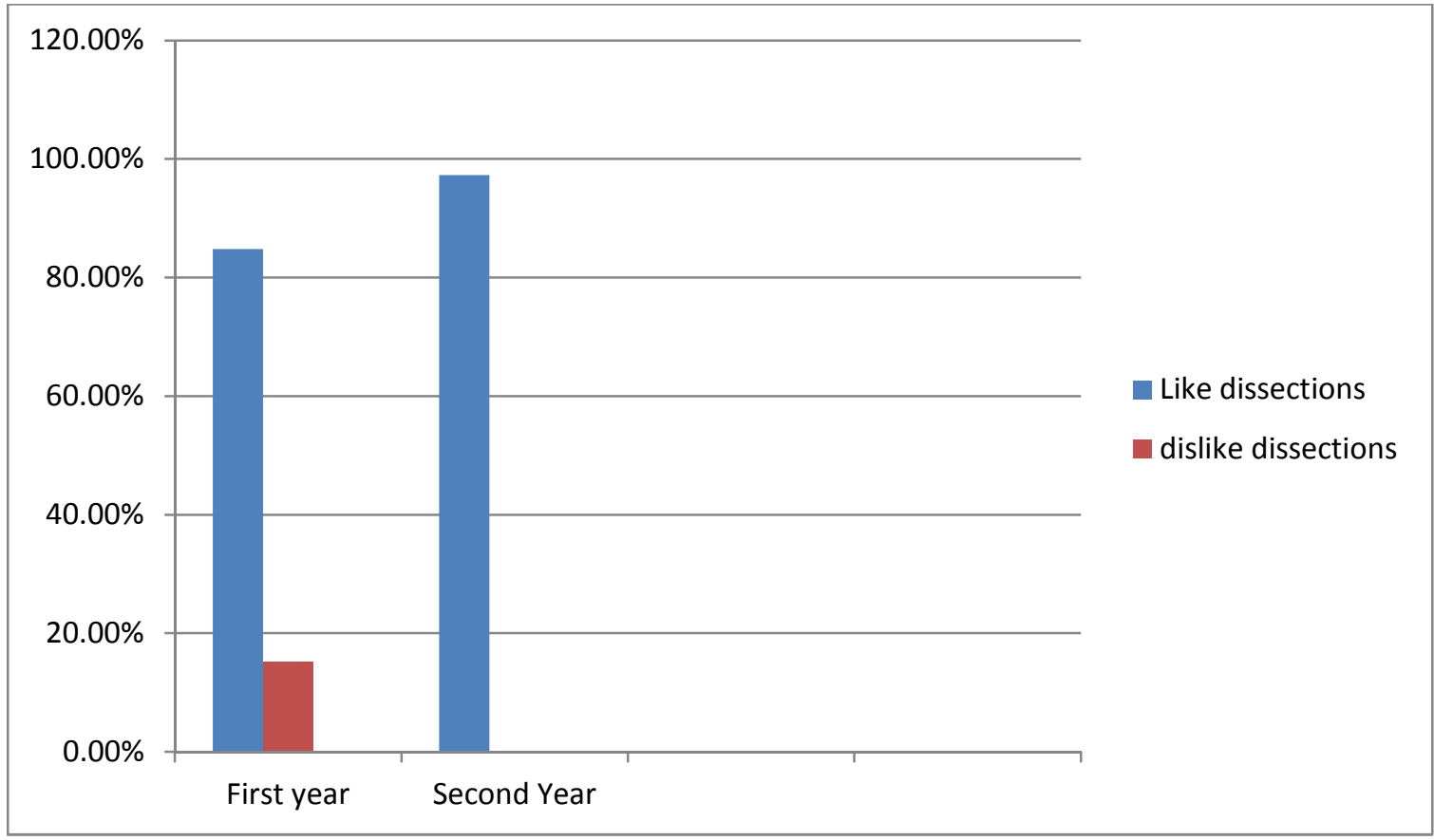

\section{Chart 1: Preference of students each teaching tool}

This was not noticed among the second year students.

Among the second year students, $95.6 \%$ of the students felt that pre-dissected specimens did distance them from the context of the human body as a whole compared to the dissection of a cadaver.

Both first year as well as second year students agreed that both teaching tools should be used in the teaching of human anatomy.

\section{Discussion}

In Sri Lanka where this study was undertaken, due to the major religion in the country being Buddhism, it is believed by the community that donating ones' remains after demise is a highly meritorious act. Hence, the supply of cadavers to medical schools is not of concern. Further, the donation is made at no cost and there is no financial liability on the universities in this respect.

The cadavers are preserved by injecting formaldehyde solution into the femoral vein and subsequently having them immersed in formaldehyde and glycerine solution in preservation tubs. The dissection rooms are fully air conditioned with exhaust fans amply positioned. The cadavers are laid on 10-15 ceramic dissection tables with running water available at each dissection table.
It is evident from the results that during the first year students find that pre-dissected specimens are helpful as much as or even more than dissections. The results we derived out of our study are comparable to a similar study conducted in Pune, India by Siddharth et al ${ }^{1}$. During the first year, students have some difficulties accustoming themselves to dissecting a human cadaver where as they seem to be more comfortable, handling pre-dissected specimens. It can be a daunting task for a student who has just cleared his advanced levels and in his late teens to confront a formaldehyde preserved human cadaver and commence dissections. During the advance level school years prior to university entry, students will learn the basics of human anatomy under the subject of biology and perhaps be exposed to few pre-dissected specimens. As soon as a student gains entry into the medical school, during their late teens, facing a cadaver and having to dissect it can be emotionally challenging as well as being a physical challenge. This reflected in the results obtained with regards to the first year students, and a minority of them did have an apprehension in dissecting a cadaver. It is interesting to note that the majority of the students who had difficulties were female students. This is also reflected in the Indian study ${ }^{1}$ as well as in few other studies published previously $2,3,4$.

In the second year with more experience gained and with maturity, students appreciated that 
dissecting a cadaver was more helpful in learning human anatomy and additionally, it did help them with gaining manual dexterity with regards to their future in surgical speciality related training. Once again this was the experience in India as well ${ }^{1}$. Second year senior students were more comfortable in dissections and appreciated the human body as a whole during the dissections of a cadaver, more than in the case of using pre-dissected specimens as a teaching and a learning tool. However they did acknowledge that in the case certain regions of the human body, pre-dissected specimens were an adjunct to their understanding of the subject.

\section{Conclusions}

Cadaveric dissections, as well as pre-dissected specimens, play an important role in the teaching of human anatomy. Cadaveric dissection provides the opportunity for students to gain a much more comprehensive insight into the human body in more holistic context. Dissections also help to develop skills which may be helpful to students who intend to follow further training in surgical specialities.

\section{References}

1. Siddharth Dubhashi, Usha Dubhashi, Amarjit Singh, Trinath T; Medical students react to cadaveric dissections. Recent research in science and technology; 2001; 3(1):135-138

2. Charlton R, Doney SM, Jones DG, Blunt A; Effects of cadaveric dissection on the attitudes of medical students. Medical education; 1994; 28(4): 290-295

3. Dinsmore CE, Daugherty S, Zeits HJ; Student response to the gross anatomy laboratory in the medical curriculum. Clinical Anatomy; 14(3): 231-236

4. Evans EJ, Fitzgibbon GN, The dissection room-reaction of the first year medical students. Clinical Anatomy; 1992; 5: 311-320

\section{Questionnaire}

\section{Your preference in teaching anatomy matters!}

\section{Study on student preference on human anatomy teaching tools}

Please note that instructions on filling this questionnaire can be obtained from your allocated anatomy demonstrator who are fully trained in providing you with standardised instructions. Information gathered in this study will be for the purpose of assessing your preference of teaching tools in the teaching process of human anatomy. No person identification details are required in this questionnaire. Please don not provide any identification details.

\section{Demographic Details}

$\begin{array}{llll}\text { Batch year } & \text { first year } & \text { second year } & \text { (Please delete irrelevant answer) } \\ \text { Gender } & \text { Male } & \text { female } & \text { (Please delete irrelevant answer) }\end{array}$

\section{Your preference and opinion on teaching tools}

1. Do you prefer formaldehyde preserved cadavers for dissections? Yes No
a. (Please delete irrelevant answer)

2. Do you prefer pre-dissected specimens for the teaching of anatomy?Yes No

a. (Please delete irrelevant answer)

b. If yes, please give reasons(you are able to tick more than one response)
i. Develops hand eye coordination
yes no
ii. Helps you to develop skills needed for a future career in surgery-yes
no
iii. Helps you to understand the subject in a broader context yes
iv. It makes you feel closer to the human body yes no

c. If no, please give reasons (you are able to tick more than one response)
i. Cadavers are unpleasant and scarery
yes no 
ii. I am uncomfortable due to the formaldehyde yes no

iii. Cadavers are not necessary for teaching anatomy- yes no

3. Do you prefer Pre-dissected specimens(PDS) more than cadavers for teaching?

a. (Please delete irrelevant answer)

b. If yes please give reasons
i. PDSs are more easily understood
yes no
ii. Saves time
yes no
iii. Less messy
yes
no

c. If no, please give reasons

i. PDSs, do not allow development of hand eye coordination-yes

no

ii. PDSs, are not very helpful in projecting a holistic picture- yes

no

iii. PDSs distance me from the human body

yes

no 